\title{
Radiation protection in radiotherapy is too conservative
}

\author{
James Rijken ${ }^{1} \cdot$ Cameron Jeffries $^{2}$. Clive Baldock ${ }^{3}$
}

Accepted: 29 July 2021 / Published online: 3 August 2021

๑) Australasian College of Physical Scientists and Engineers in Medicine 2021

\section{Introduction and overview: Clive Baldock, moderator}

Radiation protection is an important consideration in radiotherapy whether it be regarding patient treatments or the safety of patients, personnel and members of the public. Although there are accepted standards, published regulations and codes of practice supported by research, there remains debate. In this spirited topical debate, James Rijken and Cameron Jefferies, both from South Australia, debate this important subject.

Arguing for the proposition is James Rijken PhD. Dr Rijken works at Icon Cancer Centre Windsor Gardens in Adelaide, Australia where he is the site senior physicist. James' first interest in radiation safety came about in his undergraduate degree when studying astrophysics at the University of Adelaide. Not wanting a career watching the stars, he changed to something radiation related but a bit closer to home with an MPhil under Dr Judith Pollard. This led to a medical physics technician position at the Royal Adelaide Hospital, which involved managing radioactive waste including some old cobalt and plutonium! After moving to Adelaide Radiotherapy Centre for his Training Education and Assessment Program (TEAP) studies, he was once again able to delve into radiation safety through his $\mathrm{PhD}$ at Queensland University of Technology where he studied remotely under Associate Professor Jamie Trapp, publishing two papers on linear accelerator bunker shielding. Now working at Icon Cancer Centre, James chairs the Radiation Safety Technical Stream for Australia and New Zealand

Clive Baldock

cbaldock@uow.edu.au

1 Icon Cancer Centre Windsor Gardens, Adelaide, SA, Australia

2 Medical Physics \& Radiation Protection Group, South Australia Medical Imaging, Flinders Medical Centre, Adelaide, SA, Australia

3 Research and Innovation Division, University of Wollongong, Wollongong, NSW 2522, Australia as well as acting as radiation safety delegate for his site in Windsor Gardens. He continues to engage in research in the area of radiation protection when he has the chance, inbetween clinical duties, other project work and assisting the Australasian College of Physical Scientists \& Engineers in Medicine (ACPSEM) as a member of both the South Australia and Northern Territory ACPSEM Branch Committee and the ACPSEM Professional Standards Board.

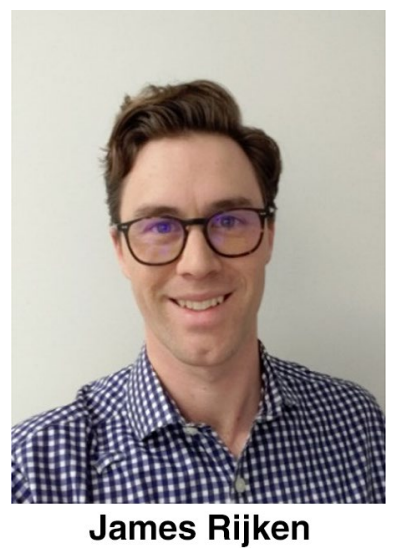

Arguing against the proposition is Cameron Jeffries. Cameron Jeffries works as a Senior Medical Physicist in the Medical Physics \& Radiation Protection group, South Australia Medical Imaging at Flinders Medical Centre. Cameron received a Master's degree in Physics from Queensland University of Technology for his research on airborne radioactivity in a mineral sand dry processing operation. After completing university, he started working in radiation protection at Olympic Dam uranium mine, South Australia. During this time, he missed visiting the Sunshine Coast on weekends. However, he developed his knowledge of environmental radioactivity and radiation protection in uranium mining. The time spend in a large mining and metallurgical processing complex highlighted the importance of a holistic approach to safety with radiation protection being only part of the overall risk picture. Cameron also undertook thousands of radon decay product measurements and 
numerous confined space clearances at Olympic Dam. Cameron moved in to regulatory roles with the New South Wales and South Australian Environment Protection Authorities where he developed an interest in practical implementation of radiation protection requirements. Cameron was part of the drafting and review group for ARPANSA's Radiation Protection Series No. 9.1: Safety Guide for Monitoring, Assessing and Recording Occupational Radiation Doses in Mining and Mineral Processing (2011). Cameron became the radiation safety officer at St Vincent's Hospital, Sydney in 2010. Cameron is passionate about a graded approach to radiation protection and achieving national uniformity in radiation protection regulation. Development of the profession, in particular widespread radiation protection literacy, is a key requirement for implementation of a uniform risk based approach to radiation protection. Cameron is a past president of the Australasian Radiation Protection Society, and a member of ACPSEM, the Australian Institute of Physics and the Health Physics Society (US). Cameron is a member of the Australasian Radiation Protection Accreditation Board and the editorial board of the Journal for Radiation Protection and Research. Cameron is also a member of the Executive Council of the International Radiation Protection Association.

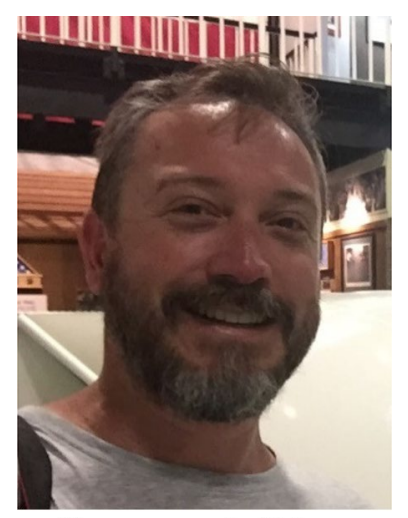

Cameron Jeffries

\section{For the proposition: James Rijken}

\section{Opening statement}

$0.1 \mathrm{mSv}$. That's the average annual occupational dose received by radiation therapists and physicists based on 30 years of Australian Radiation Protection and Nuclear Safety Agency (ARPANSA) monitoring [1]. Do we all only work $12 \mathrm{~min}$ a week in controlled areas? That seems implausible, in which case, my debate opponent has the unenviable position of showing that these figures, at the very least, indicate we have achieved the perfect level of radiation protection conservatism in radiotherapy or, further, that radiotherapy occupational doses are not low enough. Such a position could only be held under the assumption of a linear-no-threshold (LNT) model of radiation harm. However, that theory has been soundly disproven by a preponderance of evidence to the contrary [2]. Adoption of the LNT is too conservative and continues to engender radiation paranoia to this day. With hormesis at the helm, perhaps the principle of "optimisation" would only be adhered to down to a certain dose. Or maybe occupational dose limits could revert back to being around $100 \mathrm{mSv} / \mathrm{y}$, after which there is actual evidence of harm [3]. To those chary of such action, perhaps let us (for argument's sake) follow the ICRP's recommendation of lower dose limits [4]. Should we then keep adding additional layers of conservatism? ARPANSA certainly believes so, recommending facilities design shielding to meet lower dose constraints [5]. Even if we then adhered to these figures below regulatory limits, shielding protocols themselves have large factors of conservatism built in [6], culminating in over-shielding and occupational doses barely distinguishable from background [1]. For some perspective, $>30 \mathrm{mSv} / \mathrm{y}$ is a normal background exposure in certain parts of the world [7]. With respect to occupational and public doses, radiation protection in radiotherapy is simply too conservative. There are layers and layers of conservatism added, stemming back to the reliance on a LNT model of radiation harm, at huge financial and social cost [6,7]. This then be my cri de cœur: we only need one layer of conservatism. Who or which organisation has the courage to follow the science?

For completeness, a pithy remark on protection in the case of planned, medical exposure. Protection of a patient's normal tissue is usually the limiting factor in treatment delivery. Normal tissue complication probability (NTCP) modelling studies and, more recently, Quantitative Analysis of Normal Tissue Effects in the Clinic (QUANTEC) allow the clinician to categorise toxicity risk based on dose-volume parameters or model results [8]. Acceptable toxicity is all dependent on the individual patient and their situation with each patient having the principles of 'justification' and 'optimisation' applied to them. So it would be too difficult to say that whatever conservatism is currently being utilised as a whole should decrease or increase, even without the additional complication of uncertainties in induced radiosensitivity from adjuvant chemotherapy. Acknowledging this difficulty, I would like to suggest we keep the debate centred upon occupational and public exposure scenarios. 


\section{Against the proposition: Cameron Jeffries}

\section{Opening statement}

The Cancer Council advise us that radiotherapy, or radiation therapy, "uses x-rays to destroy or injure cancer cells so they cannot multiply" [9]. Radiotherapy could include a range of treatment modalities beyond $\mathrm{x}$-ray beam therapy such as brachytherapy, radioiodine, radiopharmaceuticals, and emerging ion beam therapies. To quote International Commission for Radiological Protection (ICRP) Publication 44 radiotherapy "involves achieving the optimal balance between the efficacy of irradiation in achieving sterilization of the malignant growth and the production of the minimum of treatment-related complications." [10]. The common theme is injuring, destroying or sterilising malignant cells and growths. Significant radiation doses are required to cause such biological effects (deterministic radiation effects) in human cells.

In a nutshell everyone needs to be protected-staff, patients, carers and the public. The level of protection varies widely depending on who is being protected. Conservatism should be defined relative to the protection situation for each group of protected persons.

The System of Radiological Protection developed by the ICRP in Publication 103 [11] is based on the radiation protection principles:

\section{Justification}

Any decision that alters the radiation exposure situation should do more good than harm.

\section{Optimisation}

The likelihood of incurring exposures, the number of people exposed, and the magnitude of their individual doses should be kept as low as reasonably achievable, taking into account economic and societal factors.

\section{Limitation}

The total dose to any individual from regulated sources in planned exposure situations other than medical exposure of patients should not exceed the appropriate limits [recommended by ICRP].

Justification and optimisation are source related and apply to all exposure situations, including staff and patients. Deriving a benefit that is greater than imparted risk is a widely accepted standard of almost all human activities, and especially for patient care in medicine. Justification of radiation exposure is not 'too conservative'.

ICRP Publication 105 provides the following advice on optimisation of patient exposure to radiation [12].

There is also a growing number of deterministic injuries (tissue reactions) resulting from unnecessarily high doses from the use of fluoroscopy during interventional procedures. In addition, in radiation oncology, the tolerance for deviation from the treatment regimen is very small. Usually, overdosage in excess of $10 \%$ will result in an unacceptably high risk of complications. Underdosage will result in failure to cure the cancer and will lead to more cancer deaths than expected.

Radiotherapy needs to give the correct dose to the patient to cure cancer and to minimise complications. The risk of radiation induced second malignancies is recognised as a possible complication of radiotherapy with steps being taken to identify contributing factors to their development [13]. This work has even advanced to the point of comparing the role of treatment technology in the induction of secondary cancers [14]. Optimisation of protection in radiotherapy occurs as part of good clinical practice, not an imposed requirement of radiation protection.

Limitation only applies to planned exposure situations, but critically not to the planned exposure of patients. The use of the LNT hypothesis as a basis for setting radiation dose limits is a matter of considerable debate [15]. In general, the use of LNT to set dose limits is probably too conservative. However, radiotherapy is not part of the general case. The radiation fields used in radiotherapy are very large, and staff must be excluded from treatment rooms. Dose limit compliance is trivial when staff are not exposed to radiation.

Radiotherapy is driven by an imperative to induce radiation effects in cancers while minimising complications to patients. Compared to the restrictions imposed by clinical practice, radiation protection in radiotherapy is not too conservative.

\section{For the proposition: James Rijken}

\section{Rebuttal statement}

Considering both our expertise and the scope of this journal I considered the debate would centre on public and occupational exposure. The only thing my colleague has mentioned of the sort is an assent to LNT being indeed too conservative-so I need not defend my position again.

Instead my opponent has centred his argument on radiation protection of the patient. This is an excellent topic covered by ICRP [10] but it seems a debate would be better 
suited between our colleagues at the Royal Australian and New Zealand College of Radiologists (RANZCR) since justification lies with the medical profession [4]. Notwithstanding, my colleague's argument can be reduced to the following: radiotherapy needs to be given with the correct dose otherwise there will complications. Please reread my opening statement, outlining how these notions are difficult to apply, for or against, due to the individual nature of patient treatment. That being said, my rebuttal is that it is more complicated than my opponent proposes since it is necessary to differentiate between target and organs at risk (OAR) dose [16].

History shows us that OAR limits are subject to change, sometimes being proven to be too conservative [17]. As for target doses, the statement that "radiotherapy [can] include a range of treatment modalities beyond $\mathrm{x}$ ray beam therapy such as brachytherapy..." etc. and "tolerance for deviation from the treatment regimen is very small" somewhat presents as an aporia. Why do these extra modalities exist if not to maximise the biological effective dose to the target? Consider if we were to treat a current prostate patient with a four-field box using prescriptions and margins from 1990. If volumetric modulated arc therapy (VMAT) is available, should we call our rudimentary approach too conservative? Most likely. And how much more conservative would it be compared to emerging and future techniques? In fact, the basic assumption that we can indeed make our prescriptions/ margins less conservative is the main driver for research and improved patient outcomes and accessibility. Otherwise, why go to the extent of intra-operative radiotherapy or brachytherapy or why invest billions in particle therapy, stereo and FLASH?

\section{Against the proposition: Cameron Jeffries}

\section{Rebuttal statement}

My colleague seems to be confusing LNT with the application of a risk based approach to radiation protection. "Layers and layers of conservatism" is a choice made by individual practitioners. Radiation protection principles are not prescriptive rules, rather they allow wide scope in their application. It's certainly possible to satisfy radiation protection principles using a realistic approach to shielding [18]. However, a retrospective review of existing operations uses vital data not available for prospective radiation protection assessment.

Outright rejection of the LNT hypothesis hinders understanding of its uses and limitations. RPS C-1 does not invoke LNT for setting dose constraints [5]. LNT is useful for predicting the future in the absence of actual radiation protection data. In fact, Streffer concludes there is no avoiding LNT for "prospective radiological protection" [3].

Reported occupational doses confirm my view that operational requirements control dose, not conservative bunker design. The base case bunker in Rijken et al. implies an IDR that is consistent with $0.28 \mathrm{mSv}$ annually [6]. An annual dose of $0.28 \mathrm{mSv}$ compared to a dose constraint of $10 \mathrm{mSv} /$ $\mathrm{yr}$ provides a dose saving of $\sim 107 \mathrm{mSv}$, for a model workforce [19].

A value of US $\$ 1000$ per $\mathrm{mSv}$ has been used to define reasonable in medical imaging [20]. This equates to $\sim \$ 1.1$ million over a 10-year lifetime, avoiding $1070 \mathrm{mSv}$ in total. The worst-case cost of conservatism $(\$ 300,000$ [6]) is economically reasonable by this measure. While there may be conservatism in radiotherapy, it's not 'too conservative'.

What is the cost of a shielding prediction being wrong?

\section{References}

1. Litwin M (2019) Occupational radiation doses in medical professions - a review of 30 years of data from the ARPANSA PRMS database. Australas Phys Eng Sci Med 42:285-401

2. Vaiserman AM (2010) Radiation hormesis: historical perspective and implications for low-dose cancer risk assessment. Dose Response 8:172-191

3. Streffer C (2010) Radiological protection: challenges and fascination of biological research. International Atomic Energy Agency (IAEA), IAEA

4. ICRP (2007) The 2007 recommendations of the international commission on radiological protection. Ann ICRP 37:2-4

5. Australian Radiation Protection and Nuclear Safety Agency (ARPANSA) (2016) Radiation Protection in Planned Exposure Situations. Radiation Protection Series C-1. https://www.arpan sa.gov.au/regulation-and-licensing/regulatory-publications/radia tion-protection-series/codes-andstandards/rpsc-1. Accessed 28 Feb 2021

6. Rijken J, Bhat M, Crowe S et al (2019) Conservatism in linear accelerator bunker shielding. Australas Phys Eng Sci Med 42:781-787

7. Bhat M (2010) Fear of radiation is frightening. Australas Phys Eng Sci Med 33:215-217

8. Bentzen SM, Constine LS, Deasy JO et al (2010) Quantitative analyses of normal tissue effects in the clinic (QUANTEC): an introduction to the scientific issues. Int J Radiat Oncol Biol Phys 76:S3-S9

9. Cancer Council (2021). Treatment Methods-Radiation Therapy. https://www.cancer.org.au/cancer-information/treatment/radia tion-therapy. Accessed 28 Feb 2021

10. ICRP (1985) Protection of the patient in radiation therapy. Ann ICRP 15:2 (ICRP Publication 44)

11. ICRP (2007) The 2007 recommendations of the international commission on radiological protection. Ann ICRP 37:2-4 (ICRP Publication 103)

12. ICRP (2007) Radiological protection in medicine. Ann ICRP $37: 6$ (ICRP Publication 105)

13. Dracham CB, Shankar A, Madan R (2018) Radiation induced secondary malignancies: a review article. Radiat Oncol J 36:85-94

14. Lee HF, Lan JH, Chao PJ et al (2018) Radiation-induced secondary malignancies for nasopharyngeal carcinoma: a pilot 
study of patients treated via IMRT or VMAT. Cancer Manag Res 10:131-141

15. Calabrese EJ, O'Connor MK (2014) Estimating risk of low radiation doses - a critical review of the BEIR VII report and its use of the linear no-threshold (LNT) hypothesis. Radiat Res 182:463-474

16. ICRP (1996) Radiological protection and safety in medicine. Ann ICRP 26:2 (ICRP publication 73)

17. Schultheiss TE, Kun LE, Ang K-K et al (1995) Radiation response of the central nervous system. Int J Radiat Oncol Biol Phys 31:1093-1112

18. Jeffries C, Freeman N, Nasreen F et al (2016) Shielding assessment and radiation exposure adjacent to a linear accelerator treatment bunker with a highlight window. Radiat Prot Australas 33:17-23

19. Smith LJ, Kearvell R, Arnold AJ (2016) Radiation therapy staffing model 2014. J Med Radiat Sci 63:209-216

20. Lambert K, McKeon T (2001) Inspection of lead aprons: criteria for rejection. Health Phys 80:S67-S69

Publisher's Note Springer Nature remains neutral with regard to jurisdictional claims in published maps and institutional affiliations. 